\title{
Stunting among primary-school children: a sample from Baghdad,
} Iraq

\author{
A.J.Al-Saffar
}

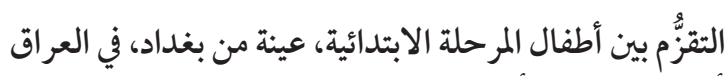

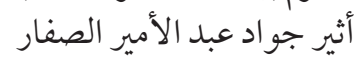

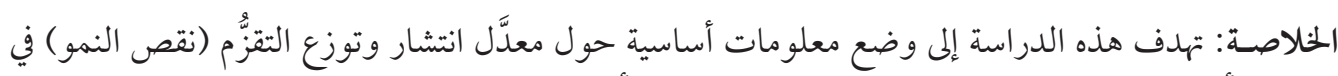

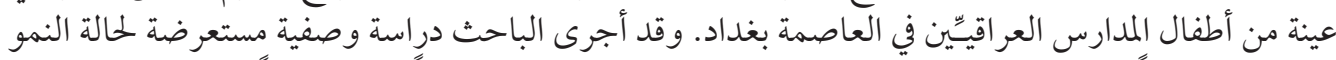

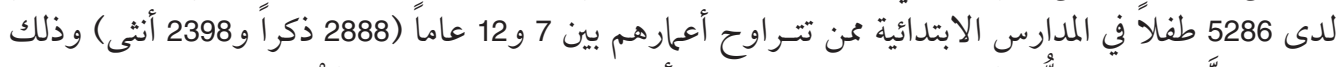

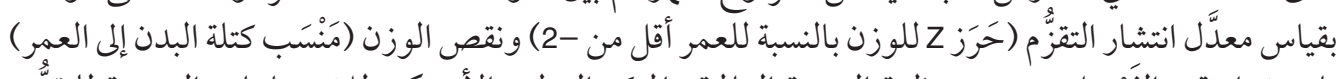

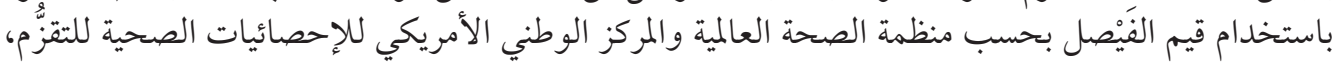

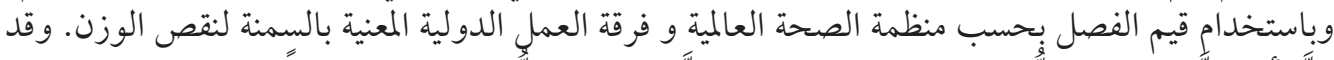

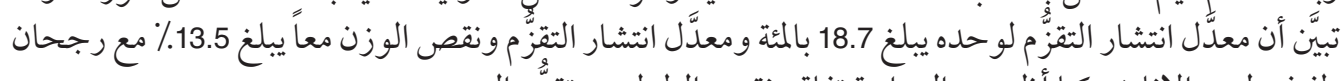

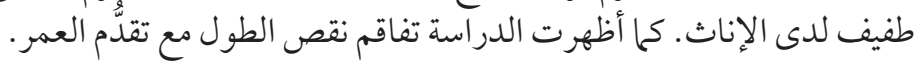

ABSTRACT The aim of this study was to establish baseline information about the prevalence and distribution of growth deficit (stunting) in a sample of Iraqi schoolchildren from the capital, Baghdad. A cross-sectional descriptive analysis of the growth status of 5286 primary-school children aged 7-12 years (2888 males, 2398 females) was conducted by measuring the prevalence of stunting (height-forage Z-score <-2), and underweight (body mass index-for-age) using the NCHS/WHO and IOTF/WHO cutoff values respectively. The prevalence of stunting only, and concurrent stunting and underweight, were $18.7 \%$ and $13.5 \%$ respectively, with a slight predominance among girls. The study also demonstrated the progression of height deficit with increasing age.

\section{Retard de croissance chez les enfants des écoles primaires : étude d'un échantillon à Bagdad (Iraq)}

RÉSUMÉ La présente étude avait pour objectif de réunir des données de référence sur la prévalence et la répartition du retard de croissance dans un échantillon d'enfants iraquiens vivant dans la capitale, Bagdad. Une analyse descriptive transversale de la croissance a été réalisée chez 5286 enfants des écoles primaires âgés de 7 à 12 ans (2 888 garçons et 2398 filles) grâce à la mesure de la prévalence du retard de croissance (valeur du Z pour le rapport taille/âge $<-2$ ) et du déficit pondéral (indice de masse corporelle pour l'âge), sur la base, respectivement, des seuils NCHS/OMS et IOTF/OMS. La prévalence du retard de croissance s'élevait à $18,7 \%$ et celle du retard de croissance et du déficit pondéral à $13,5 \%$, avec une légère prédominance chez les filles. L'étude a également démontré la progression du déficit de taille à mesure que l'âge augmente.

\footnotetext{
${ }^{1}$ Department of Community Medicine, College of Medicine, Al-Nahrain University, Baghdad, Iraq (Correspondence to A.J.Al-Saffar: atheer4867@hotmail.com).

Received: 08/06/06; accepted: 03/10/06
} 


\section{Introduction}

The best global indicator of a child's wellbeing is growth: infections and poor nutrition, or usually a combination of both, are major factors affecting physical growth and mental development $[1,2]$.

While height is to a large extent genetically determined, it also reflects a child's socioeconomic, health and nutritional status [2]. Undernutrition is not just a state, but a process, whose consequences often extend not only into later life, but also into future generations [1]. It is a cumulative process that starts in utero and is clearly linked with low birthweight. There is substantial evidence that intrauterine growth is a strong predictor of postnatal growth and final height is determined in large part by nutrition from conception to age 2 years. Stunting is defined identically in childhood and during adolescence as height less than $-2 \mathrm{Z}$ scores below that expected on the basis of the international growth reference $[1,3]$.

Stunting is associated with impaired mental development and poor school performance later on. This association is not a simple causal one because complex environmental, social and economic factors interfere [1-4].

Height has been shown to be related to productivity, and a $1 \%$ loss in adult height as a result of childhood stunting is associated with a $1.4 \%$ loss in productivity [1]. However, data on the growth of school-age children, generated in a consistent manner across countries and over time, is difficult to find $[3-6]$.

The present study was therefore undertaken in order to describe the nutritional status of male and female schoolchildren aged 7-12 years in Baghdad, Iraq, through focusing on stunting, to provide baseline information about the prevalence and distribution of this problem.

\section{Methods}

\section{Setting}

This cross-sectional study was conducted in primary schools in Baghdad (the capital of Iraq) during the 2nd semester of the academic year 2004/05. The sample comprised $5 \%$ of the primary schools in the city, chosen by a simple random technique from each of the 2 major districts of the capital (Karkh and Russafa), proportionate to the number of schools in each district and to the population density. The sample was all the students aged $7-12$ years in 26 primary schools (boys and girls, separate or mixed), 14 in Rusafa and 12 in Karkh; 1 school in each group was from a rural area.

All approvals from the Ministry of Education were prepared and a timetable was constructed to visit the schools in a systematic manner during March and April before the final examinations.

\section{Measurements}

The recorded parameters were age, height and weight. Age information was obtained from the child's reporting. The anthropometric data were collected at schools by 6 well-trained data collectors working in pairs. Weight was measured using a calibrated digital scale for all boys and girls wearing light clothing with an accepted error of $0.1 \mathrm{~kg}$. Height was measured for all children without shoes using a wall-mounted stadiometer (Microtoise, Stanley Mabo, France) with an accepted error of $0.1 \mathrm{~cm}$.

The data were used to calculate:

- height-for-age, the anthropometric indicator used to evaluate stunting;

- body mass index (BMI)-for-age, to evaluate underweight. BMI was calculated from the height and weight data using the standard formula: weight (kg)/ height $^{2}(\mathrm{~m})$. 
BMI-for-age and height-for-age Zscores were calculated for each individual, assuming mid-year age for each child because of doubts over the correct date of birth. The National Center for Health Statistics (NCHS)/World Health Organization (WHO) reference values for height [7] and the International Obesity Task Force (IOTF)/WHO $[8,9]$ cutoff values for weight were used to estimate age-specific prevalence of stunting and underweight, according to the recommendations made by the WHO Expert Committee [3]. Stunting was defined as Z-value below -2 standard deviations (SD) of the expected median of the NCHS/WHO cutoff values for height [7].

\section{Statistical analysis}

Frequencies, relative and cumulative percentages, means, standard deviation (SD), and range were computed. Chi-squared for linear trend was calculated when applicable. The chi-squared standard test was used to test for associations in categorical variables and the $F$-test for continuous variables. The correlation coefficient was calculated to measure the relation between the variables. $P$-value $\leq 0.05$ was considered statistically significant. Data were analysed using EpiInfo 2000 and SPSS, version 11.

\section{Results}

A total of 5286 children formed the study cohort. Of these, $54.6 \%$ were males and
$45.4 \%$ were females, a male:female ratio of $1.2: 1$. The mean age was 10.1 [standard deviation (SD) 1.5, range 7-12] years, and the mean height was 134.9 (SD 11.0) cm.

Using the cutoff value of $-2 \mathrm{Z}$-scores of height-for-age, the overall prevalence of stunting was $18.7 \%$, with a mean height of $126.2(\mathrm{SD} 8.07) \mathrm{cm}$, while the prevalence of linear growth deficit (lower than -1 SD of the median of the NCHS $\backslash \mathrm{WHO}$ ) in the same age group was $53.3 \%$ (Table 1 ).

The prevalence of stunting rose steadily and significantly with age $(r=0.737, P$ $=0.01$ ), from an overall of $7.7 \%$ in 7 -yearolds to $22.4 \%$ in 12 -year-olds (Table 2). No statistically significant difference was found in the sex distribution of the sample, females $(19.1 \%)$ were, however, slightly more stunted than males $(18.3 \%)$ (Table 3$)$.

Applying sex stratification, it was noted that the prevalence of stunting rose with age in a statistically significant way in comparison to normal height students (for males $\chi^{2}$ for linear trend $=19.69 ; P<0.001 ; r=0.717$ and for females $\chi^{2}$ for linear trend $=26.37, P$ $<0.001, r=0.761$ ) (Table 4). Moreover, the age distribution of the 987 stunted students showed that about one-third of the stunted males $(31.1 \%)$ were 12 years old, while the peak rate for stunted females $(27.5 \%)$ was at 11 years of age (Table 5).

Significantly more of the stunted students $(13.5 \%)$ were underweight compared to normal height students $(7.8 \%)(P<0.001)$ (Table 6).

\begin{tabular}{|c|c|c|c|c|c|}
\hline Stunting & No. & $\%$ & Cumulative \% & $\begin{array}{l}\text { Mean height } \\
\text { (cm) }\end{array}$ & SD \\
\hline$<-2$ SD height & 987 & 18.7 & 18.7 & 126.2 & 8.1 \\
\hline-1 to -2 SD height & 1828 & 34.6 & 53.3 & 132.3 & 8.6 \\
\hline Normal height & 2471 & 46.7 & 100.0 & 140.2 & 10.6 \\
\hline Total & 5286 & 100.0 & & 134.9 & 11.0 \\
\hline
\end{tabular}

$\mathrm{F}=868.3 ; \mathrm{P}<0.001$.

$S D=$ standard deviation. 


\begin{tabular}{|c|c|c|c|c|c|c|c|c|}
\hline \multirow{3}{*}{$\begin{array}{l}\text { Age } \\
\text { (years) }\end{array}$} & \multicolumn{6}{|c|}{ Height } & \multirow{2}{*}{\multicolumn{2}{|c|}{ Total }} \\
\hline & \multicolumn{2}{|c|}{$-2 S D$} & \multicolumn{2}{|c|}{-1 to -2 SD } & \multicolumn{2}{|c|}{ Normal } & & \\
\hline & No. & $\%$ & No. & $\%$ & No. & $\%$ & No. & $\%$ \\
\hline 7 & 27 & 7.7 & 91 & 25.9 & 233 & 66.4 & 351 & $100.0(6.6)^{\mathrm{a}}$ \\
\hline 8 & 87 & 14.6 & 212 & 35.5 & 298 & 49.9 & 597 & $100.0(11.3)^{a}$ \\
\hline 9 & 172 & 18.0 & 378 & 39.7 & 403 & 42.3 & 953 & $100.0(18.0)^{a}$ \\
\hline 10 & 196 & 19.9 & 322 & 32.6 & 468 & 47.5 & 986 & $100.0(18.7)^{\mathrm{a}}$ \\
\hline 11 & 226 & 19.6 & 401 & 34.7 & 528 & 45.7 & 1155 & $100.0(21.9)^{\mathrm{a}}$ \\
\hline 12 & 279 & 22.4 & 424 & 34.1 & 541 & 43.5 & 1244 & $100.0(23.5)^{a}$ \\
\hline Total & 987 & 18.7 & 1828 & 34.6 & 2471 & 46.7 & 5286 & 100.0 \\
\hline
\end{tabular}

apercentage by row.

$\chi^{2}=92.4 ; P<0.001$.

$S D=$ standard deviation.

\section{Discussion}

Stunting may be a better cumulative indicator of well-being for populations of children in countries than underweight because underweight is affected by weight recovery for some children between 2 and 5 years of age and by some children being overweight. This can be explained by the fact that children who are stunted early in life may attain normal weight later on but remain short [2].

Iraq is a developing country experiencing constraints on economic and social development and most of the environmental factors that affect the physical growth of children before puberty, including poor food consumption patterns, illness, lack of sanitation, poor hygiene practices and poor health care coverage and resources, are present. Almost half of Iraq's total population of 27 million are children. United Nations agencies estimate that 1 out of 8 Iraqi children dies before the age of 5 years; one-third are malnourished; one-quarter are born underweight and one-quarter do not have access to safe water [10]. Rates for stunting among children under the age of 5 years in southern and central Iraq peaked in 1996 at $32.0 \%$, and then declined to $23.1 \%$ in 2002 [10]. Iraq was classified by the World Bank among the category A countries that have underweight or stunting rates $>0 \%$ in children under 5 years old [1].

Chronic undernutrition, as evidenced by the proportion of stunted children, was of mild prevalence in this school-aged cohort

\begin{tabular}{|c|c|c|c|c|c|c|c|c|}
\hline \multirow[t]{3}{*}{ Sex } & \multicolumn{6}{|c|}{ Height } & \multicolumn{2}{|c|}{ Total } \\
\hline & \multicolumn{2}{|c|}{$-2 \mathrm{SD}$} & \multicolumn{2}{|c|}{-1 to -2 SD } & \multicolumn{2}{|c|}{ Normal } & \multirow[b]{2}{*}{ No. } & \multirow[b]{2}{*}{$\%$} \\
\hline & No. & $\%$ & No. & $\%$ & No. & $\%$ & & \\
\hline Male & 528 & 18.3 & 1009 & 34.9 & 1351 & 46.8 & 2888 & $100.0(54.6)^{a}$ \\
\hline Female & 459 & 19.1 & 819 & 34.2 & 1120 & 46.7 & 2398 & $100.0(45.4)^{a}$ \\
\hline Total & 987 & 18.7 & 1828 & 34.6 & 2471 & 46.7 & 5286 & 100.0 \\
\hline
\end{tabular}

a Percentage by row.

$\chi^{2}=0.75 ; \mathrm{P}=0.69$.

$S D=$ standard deviation.

المجلة الصحية لشرق المتوسط، منظمة الصحة العالمية، المجلد الخامس عشر، العدد ب، 9 ب. 


\begin{tabular}{|c|c|c|c|c|c|}
\hline \multirow{3}{*}{$\begin{array}{l}\text { Sex/age } \\
\text { (years) }\end{array}$} & \multirow[t]{3}{*}{ Total } & \multicolumn{4}{|c|}{$\begin{array}{l}\text { Height } \\
\end{array}$} \\
\hline & & \multicolumn{2}{|c|}{-2 SD } & \multicolumn{2}{|c|}{ Normal } \\
\hline & & No. & $\%$ & No. & $\%$ \\
\hline \multicolumn{6}{|l|}{ Male } \\
\hline 7 & 151 & 9 & 6.0 & 106 & 70.2 \\
\hline 8 & 355 & 63 & 17.7 & 170 & 47.9 \\
\hline 9 & 503 & 87 & 17.3 & 224 & 44.5 \\
\hline 10 & 542 & 105 & 19.4 & 272 & 50.2 \\
\hline 11 & 596 & 100 & 16.8 & 272 & 45.6 \\
\hline 12 & 741 & 164 & 22.1 & 307 & 41.4 \\
\hline \multicolumn{6}{|l|}{ Female } \\
\hline 7 & 200 & 18 & 9.0 & 127 & 63.5 \\
\hline 8 & 242 & 24 & 9.9 & 128 & 52.9 \\
\hline 9 & 450 & 85 & 18.9 & 179 & 39.8 \\
\hline 10 & 444 & 91 & 20.5 & 196 & 44.1 \\
\hline 11 & 559 & 126 & 22.5 & 256 & 45.8 \\
\hline 12 & 503 & 115 & 22.9 & 234 & 46.5 \\
\hline \multicolumn{6}{|l|}{ Total } \\
\hline Male & 2888 & 528 & 18.3 & 1351 & 46.8 \\
\hline Female & 2398 & 459 & 19.1 & 1120 & 46.7 \\
\hline All & 5286 & 987 & 18.7 & 2471 & 46.7 \\
\hline
\end{tabular}

For males: $\chi^{2}$ for linear trend $=19.69 ; \mathrm{P}<0.001$. For females $\chi^{2}$ for linear trend $=26.37 ; P<0.001$. $S D=$ standard deviation.

(18.7\%) and the overall prevalence of linear growth deficit was $53.3 \%$. Subtracting the normal baseline or expected prevalence of stunting of $2.3 \%$ of the normally distributed population [7], the remaining prevalence was $16.4 \%$. This is below the prevalence of stunting $(22.2 \%)$ reported in the Administrative Committee on Coordination/ Sub-Committee on Nutrition (ACC/SCN) 3rd report on the world nutrition situation for the Near East/North Africa region [2]. Several studies from developing countries reported similar prevalence data for stunting: $6.2 \%-15.2 \%$ in public schools in Brazil in 1990 [11], 15.8\% in Nigeria in 2000 [12], $12.7 \%$ (at age 7 years) to $18.8 \%$ (at age 12 years) in Indian school-aged boys [13], $18.7 \%$ in Chad in 2002 [4], $15 \%-40 \%$ in
South Africa in 2003 [14], 25\% in Morocco in 2004 [15], 18.3\% in Kenya in 2005 [6], and $16.5 \%$ in rural areas of southern Pakistan in 2005 [16].

Although patterns of school attendance have not been described for this particular population, primary school enrolment in Iraq is 95\% according to a report of the Ministry of Planning in 2004, and the dropout from school is about $30 \%$, usually not in the early years of schooling [17]. However, school enrolment and dropout patterns may differ in stunted and non-stunted children, creating a spurious picture of stunting by age among children who attend school. Studies in Sub-Saharan Africa suggest that the prevalence of undernutrition may be greater in children not enrolled in school; therefore, the proportions found in this school-based sample are likely to under-

\begin{tabular}{lcc}
\hline \multicolumn{3}{l}{$\begin{array}{l}\text { Table } 5 \text { Age distribution of the stunted } \\
\text { students according to sex }\end{array}$} \\
$\begin{array}{l}\text { Sex/age } \\
\text { (years) }\end{array}$ & No. SD height & $\%$ \\
\hline Male & & 1.7 \\
7 & 9 & 11.9 \\
8 & 63 & 16.5 \\
9 & 87 & 19.9 \\
10 & 105 & 18.9 \\
11 & 100 & 31.1 \\
12 & 164 & $100.0(18.3)^{\mathrm{a}}$ \\
Total & 528 & \\
Female & & 3.9 \\
7 & 18 & 5.2 \\
8 & 24 & 18.5 \\
9 & 85 & 19.8 \\
10 & 91 & 27.5 \\
11 & 126 & 25.1 \\
12 & 115 & $100.0(19.1)^{\mathrm{a}}$ \\
Total & 459 & $100.0(18.7)^{\mathrm{a}}$ \\
Overall & 987 &
\end{tabular}

${ }^{a}$ Percentage by row.

$S D=$ standard deviation . 
Table 6 Relationship of height and body mass index (BMI) of the sample

\begin{tabular}{|c|c|c|c|c|c|c|c|c|}
\hline \multirow[t]{3}{*}{ BMI $^{a}$} & \multicolumn{6}{|c|}{ Height } & \multicolumn{2}{|c|}{ Total } \\
\hline & \multicolumn{2}{|c|}{$-2 S D$} & \multicolumn{2}{|c|}{-1 to -2 SD } & \multicolumn{2}{|c|}{ Normal } & & \\
\hline & No. & $\%$ & No. & $\%$ & No. & $\%$ & No. & $\%$ \\
\hline Underweight & 133 & 13.5 & 220 & 12.0 & 192 & 7.8 & 545 & 10.3 \\
\hline Normal & 752 & 76.2 & 1409 & 77.1 & 1760 & 71.2 & 3921 & 74.2 \\
\hline Overweight & 74 & 7.5 & 156 & 8.5 & 383 & 15.5 & 613 & 11.6 \\
\hline Obese & 28 & 2.8 & 43 & 2.4 & 136 & 5.5 & 207 & 3.9 \\
\hline Total & 987 & $100.0(18.7)^{\mathrm{b}}$ & 1828 & $100.0(34.6)^{b}$ & 2471 & $100.0(46.7)^{\mathrm{b}}$ & 5286 & 100.0 \\
\hline
\end{tabular}

anternational Obesity Task Force cutoff values were used for body mass index according to age [8,9].

bPercentage by row.

$\chi^{2}=127.7 ; \mathrm{P}<0.001$.

$S D=$ standard deviation.

estimate the degree of undernutrition in this age group [6]. On the other hand, there remains controversy over whether reference data from the United States of America are appropriate for children in other countries, who may have a different genetic potential for growth $[13,18,19]$, and when we include the differences in the maturation rate of poorly nourished children compared with reference healthy populations, it is clear that the interpretation of growth data in this age range is problematic [20].

Among well-nourished children, sex differences are attributed to a normal pattern of dimorphism, with males tending to be taller and heavier than females [18]. Although the data were not statistically significant, girls in this cohort were more likely to be stunted than boys, suggesting that growth in girls may be more sensitive to environmental factors such as infectious diseases, to agespecific differences in catch-up growth between the sexes or to sex-related differences in diet and child care, findings that are reported in other studies $[5,16,18,21,22]$.

It is commonly believed that stunting is mainly a problem of young children, but, although there may be some potential for catch-up growth during adolescence, recent studies suggest that children will not catch up during middle childhood if they remain in the deprived environment that caused them to become stunted in the first place. Thus, children who have become stunted are likely to remain stunted into adulthood $[6,18]$. Results from our work demonstrate the progression of height deficit in accordance with the increasing age of the children, with prevalence across age groups fluctuating from $7.7 \%$ to $22.4 \%$ below -2 $z$-scores. It is noteworthy that the increase in prevalence was steady in both sexes. In girls, the prevalence of stunting peaked at age 11 years, whereas in boys it rose steadily up to age 12 years. A similar age pattern was reported in studies demonstrating an increasing prevalence of stunting with age $[6,11,13,16,18,20,23,24]$.

The relatively low prevalence of underweight $(10.3 \%)$ in the current study indicates that a recent and severe process of weight loss was not widespread among schoolchildren. Nevertheless the prevalence of stunting and concurrent underweight was higher (13.5\%).

There are several limitations to this study that should be addressed. First, this was a school-based cohort and the findings may be affected by selection bias. On the other hand, there are many pitfalls when using cross-sectional data from schoolchildren in a search for age effects. As stunting is a

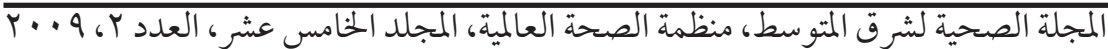


chronic phenomenon, the time factor may be one of the explanations. Older children may be more stunted than younger ones because they were more malnourished as young children, not because they are growing poorly as schoolchildren, in addition to school enrolment and drop-out patterns mentioned before. The second limitation is with respect to the accuracy of the children's dates of birth, which affects z-scores of height and weight-for-age; this was minimized by assuming the midyear age of the cutoff values for each child.

However, the present results are noteworthy because of the large sample size covering a broad age range, and they may help nutrition programme planners, who often need baseline information on the relative burden of malnutrition to decide where best to invest limited resources.

In conclusion, stunting is a common problem among primary-school children in Baghdad. This indicates that early in- tervention is vital with a need for health programmes aimed at reducing undernutrition, especially in the first 2 years of life, including the prenatal period, as stunting among schoolchildren is the result of damage that starts in utero and early childhood. The findings also highlight differences in the stunting pattern between boys and girls over time.

\section{Acknowledgements}

The author wishes to thank all the teachers and schoolchildren for participating and in the study. Gratitude is also extended to the data collectors for assistance in the fieldwork. Special thanks are due to Professor Dr Riyadh K. Lafta for his numerous corrections and valuable suggestions and his assistance with logistic support; without his work and advice, the study would have been impossible.

\section{References}

1. Repositioning nutrition as central to development: a strategy for large-scale action. Washington, DC, World Bank, 2006 (World Bank Nutrition Strategy Paper).

2. Third report on the world nutrition situation. Geneva, Administrative Committee on Coordination/Sub-Committee on Nutrition and International Food Policy Research Institute, 1997.

3. Physical status: the use and interpretation of anthropometry. Geneva, World Health Organization, 1995 (WHO Technical Report Series, No. 854).

4. Beasley $\mathrm{M}$ et al. First nationwide survey of the health of schoolchildren in Chad. Tropical medicine and international health, 2002, 7(7):625-30.

5. Anwer I, Awan JA. Nutritional status comparison of rural with urban school children in Faisalabad District, Pakistan. Rural remote health, 2003, 3(1):130.

6. Friedman et al. Progression of stunting and its predictors among school-aged children in western Kenya. European journal of clinical nutrition, 2005, 59(8):914-22.

7. WHO Global database on child growth and malnutrition. National Center of Health Statistics/World Health Organization reference data [online database] (http://www.who.int/nutgrowthdb/reference/en/, accessed 9 July 2007).

8. Giugliano D, Carneiro EC. Factors associated with obesity in school children. Jornal de pediatria, 2004, 80(1):17-22.

9. Cole TJ et al. Establishing a standard definition for child overweight and obesity worldwide: international survey. British medical journal, 2000, 320:1240-3. 
10. Briefing note on the potential impact of conflict on health in Iraq: March 2003. Geneva, World Health Organization (http://www.who.int/features/2003/iraq/ briefings/iraq_briefing_note/en/index2. html, accessed 9 July 2007).

11. Gross $R$ et al. The relationships between selected anthropometric and socioeconomic data in schoolchildren from different social strata in Rio de Janeiro, Brazil. Review saude publica, 1990, 24(1):11-9.

12. Abidoye RO, Akande PA. Nutritional status of public primary school children: a comparison between an upland and riverine area of Ojo LGA, Lagos State Nigeria. Nutrition and health, 2000, 14(4):225-40.

13. De Onis M et al. National Center for Health Statistics reference and the growth of Indian adolescent boys. American journal of clinical nutrition, 2001, 74(2):248-53.

14. Jinabhai1 CC, Taylor M, Sullivan KR. Implications of the prevalence of stunting, overweight and obesity amongst South African primary school children: a possible nutritional transition? European journal of clinical nutrition, 2003, 57:358-65.

15. Aboussaleh $Y$ et al. A diversified diet may reduce school age children stunting in North Western Morocco. Asia Pacific journal clinical nutrition, 2004, 13(Suppl.):S116.

16. Khuwaja S, Selwyn BJ, Shah SM. Prevalence and correlates of stunting among primary school children in rural areas of southern Pakistan. Journal of tropical pediatrics, 2005, 51(2):72-7.
17. Lafta RK. Drop out from schools. Iraqi journal of community medicine, 1999, 12(2):103-5.

18. Adair LS, Guilkey DK. Age-specific determinants of stunting in Filipino children. Journal of nutrition, 1997, 127(2):31420.

19. Ogden CL et al. Centers for Disease Control and Prevention 2000 Growth Charts for the United States: improvements to the 1977 National Center for Health Statistics Version. Pediatrics, 2002, 109(1):45-60.

20. Stoltzfus RJ et al. Linear growth retardation in Zanzibari school children. Journal of nutrition, 1997, 127(6):1099-105.

21. Inungu JN. Prevalence of malnutrition among school children in Ejisu-Juaben District, Ashanti region in Ghana. African journal of health science, 1995, 2(4):385-7.

22. Shubair ME et al. Intestinal parasites in relation to haemoglobin level and nutritional status of school children in Gaza. Journal of the Egyptian Society of Parasitology, 2000, 30(2):365-75.

23. Lwambo NJS et al. Age patterns in stunting and anaemia in African schoolchildren: a cross-sectional study in Tanzania. European journal clinical nutrition, 2000, 54(1):36-40.

24. Haithami SS et al. Anthropometric assessment of nutritional status and growth of children in Democratic Yemen. Journal of the Egyptian Public Health Association, 1989, 64(5-6):431-44. 